\title{
Perbedaan hasil belajar fisika siswa antara model pembelajaran Problem Based Learning (PBL) dengan model pembelajaran Prediction, Observation, and Explanation (POE) di kelas X SMA Negeri 5 Lubuklinggau
}

\author{
Tri Ariani \\ Program Studi Pendidikan Fisika, Jurusan Pendidikan MIPA STKIP-PGRI Lubuklinggau \\ J1. Mayor Toha Kelurahan Air Kuti Lubuklinggau, Sumatera Selatan, Indonesia \\ Surat-e: triariani.ta@gmail.com
}

Penelitian ini bertujuan untuk mengetahui Perbedaan Hasil Belajar Fisika Siswa antara Model Pembelajaran Problem Based Learning (PBL) dengan Model Pembelajaran Prediction, Observation, And Explanation (POE) di Kelas X SMA Negeri 5 Lubuklinggau Tahun Pelajaran 2015/2016. Jenis penelitian ini adalah penelitian kuantitatif dengan metode penelitian eksperimen semu yang dilaksanakan dengan membandingkan kelompok eksperimen I dan kelompok eksperimen II desain penelitian ini pre-test post-test group design. Populasi penelitian ini adalah seluruh siswa kelas X SMA Negeri 5 Lubuklinggau Tahun Pelajaran 20I5/20I6, yang terdiri dari 3I4 siswa dari 9 kelas. Pengambilan sampel dilakukan secara acak (Simple Random Sampling) dengan cara pengundian nomor kelas populasi. Pengumpulan data berupa tes, data tes yang sudah dianalisis dengan uji-t, pada taraf $\alpha=0,05$, diperoleh thitumg $>t_{\text {tabel }}(2,17>2,00)$. Rata-rata akhir hasil belajar fisika kelas eksperimen I sebesar 73,4 sedangkan pada kelas kelas eksperimen II sebesar 69,14. Sehingga dapat disimpulkan ada Perbedaan Hasil Belajar Fisika Siswa antara Model Pembelajaran Problem Based Learning (PBL) Dengan Model Pembelajaran Prediction, Observation, And Explanation (POE) Di Kelas X SMA Negeri 5 Lubuklinggau Tahun Pelajaran 2015/2016.

\begin{abstract}
The aim of this research was to find out the Comparative Results Between Students Studying Physics Learning Model Problem Based Learning (PBL) with Learning Model Prediction, Observation, And Explanation (POE) in the Class X SMAN 5 Lubuklinggau 2015/2016 Academic Year. This research was a quantitative research methods of experimental research conducted by comparing the experimental group I and group II experimental research design was a pre-test post-test group design. As the population in this research were all students of class X SMA Negeri 5 Lubuklinggau Academic Year 2015/20I6, consisting of 314 students from the ninth grade. Sampling is done randomly (Simple Random Sampling) by means of the draw number population class. The collection of data in the form of the test, the test data that were $=0.05$, obtained $\alpha$ analyzed by t-test, t-test based on the level of $\mathrm{t}>\mathrm{t}$ table (2.17> 2.00). The average end result of learning physics class experiment I of 73.4 while the experimental class II class at 69.14. So, it can be concluded that there Comparative Results Between Students Studying Physics Learning Model Problem Based Learning (PBL) With Learning Model Prediction, Observation, And Explanation (POE) In Class X SMAN 5 Lubuklinggau in academic year 2015/2016.
\end{abstract}

Kata kunci: Problem Based Learning (PBL), Prediction, Observation, and Explanation (POE), hasil Belajar, Uji-t

\section{Pendahuluan}

Pendidikan dipandang sebagai proses penting untuk memenuhi kelangsungan hidup bangsa dan negara serta untuk meningkatkan dan mengembangkan kualitas sumber daya manusia. Pendidikan merupakan kebutuhan yang sangat penting guna membangun manusia yang berpengetahuan, bermoral, dan bermartabat. Pendidikan harus betul-betul diarahkan untuk menghasilkan manusia yang berkualitas dan mampu bersaing, karena pendidikan 
merupakan faktor penentu kualitas suatu negara. Pada saat ini pendidikan merupakan permasalahan serius yang terjadi di negara kita. Berbagai cara dilakukan pemerintah untuk menangani problema pendidikan tersebut dengan diwujudkannya pendidikan dasar sembilan tahun dan dicanangkannya program pendidikan gratis agar setiap warga negara kita dapat menikmati pendidikan walaupun dari kalangan yang tidak mampu. semua yang dilakukan pemerintah tidak lain untuk merubah dan menyelamatkan para penerus bangsa demi menjadi negara yang bermutu dan bermatabat.

Berdasarkan hasil wawancara peneliti dengan salah satu guru mata pelajaran fisika kelas X di SMA Negeri 5 Lubuklinggau, beliau mengungkapkan bahwa adanya penurunan pencapaian kompetensi mata pelajaran fisika siswa kurang optimal dan belum sesuai dengan yang diharapkan, hal ini dapat dilihat dari nilai ulangan harian pada semester I tahun pelajaran 2014/20I5 di kelas X hanya mencapai $45,45 \%$ siswa yang dapat mencapai nilai KKM (Kriteria Ketuntasan Minimum). Hal tersebut mununjukkan bahwa 54,55\% dari 33 siswa dikelas $\mathrm{X}$ belum mencapai KKM sehingga mereka harus mengikuti remedial.

Asumsi dasar yang menyebabkan pencapaian kompetensi mata pelajaran fisika siswa kurang optimal adalah pemilihan model pembelajaran yang kurang tepat dan kurangnya peran serta keaktifan siswa dalam kegiatan belajar mengajar serta hanya menjelaskan teori saja tidak disertai percobaan. proses belajar mengajar masih terfokus pada guru dan kurang terfokus pada siswa, sehingga siswa masih cenderung kurang aktif dalam mengikuti kegiatan belajar mengajar dan siswa menjadi cepat bosan dan jenuh dalam belajar mata pelajaran fisika. Oleh sebab itu seorang guru dalam menyajikan pembelajaran harus merencanakan model yang akan digunakan, karena model dalam pengajaran sangat menentukan tercapai atau tidaknya tujuan pembelajaran.

Adapun cara untuk memotivasi siswa dan memiliki kemandirian serta keaktifan siswa dalam belajar pada pelajaran fisika ialah dengan menggunakan model pembelajaran problem based learning (PBL) dan model pembelajaran prediction, observation and explanation (POE). Kedua model tersebut merupakan model-model pembelajaran yang efektif dan efisien. namun, untuk meningkatkan hasil belajar siswa, guru membutuhkan salah satu model yang paling efektif dalam proses pembelajaran.

\section{Kajian Pustaka}

Pada penelitian ini lebih menekankan pada hasil belajar siswa ranah kognitif pada dua kelas yang di berikan perlakuan model pembelajaran yang berbeda. Kelas eskperimen I menggunakan model Problem Based
Learning (PBI) dan kelas eksperimen II diberikan perlakukan dengan menggunakn model Prediction, Observation And Explanation (POE). Ranah kognitif mencakup pengatahuan, pemahaman, analisis, sisntesis dan evaluasi. Hasil belajar kognitif siswa di ukur dengan menggunakan lembar tes yaitu pretest dan posttest.

Tampubolon ${ }^{[1]}$, Model pembelajaran Problem Based Learning (PBL) mensyaratkan keterlibatan aktif siswa sehingga terbukti dapat meningkatkan hasil belajar dan sikap anak terhadap sains. Model pembelajaran Problem Based Learning merupakan salah satu model pembelajaran yang berasosiasi dengan pembelajaran kontekstual. Pembelajaran artinya dihadapkan pada suatu masalah, yang kemudian dengan melalui pemecahan masalah, melalui masalah tersebut siswa belajar keterampilanketerampilan yang lebih mendasar.

Putra Rizema ${ }^{[2]}$, menyatakan Langkah-langkah Problem Based Learning (PBL) yaitu (a) Guru mengorientasikan siswa pada masalah, (b) Guru mengorganisasikan siswa agar belajar, (c) Guru memandu menyelidiki secara mandiri atau kelompok, (d) Guru mengembangkan dan menyajikan hasil kerja, (e) Guru menganalisis dan mengevaluasi hasil pemecahan masalah.

Selain model Problem Based Learning (PBL), untuk melibatkan siswa dalam proses belajar mengajar ialah dengan menggunakan model pembelajaran Prediction, Observation and Explanation (POE). Zulaeha ${ }^{[3]}$, menyatakan bahwa terdapat pengaruh keterampilan proses sains antara kelas yang mendapatkan pembelajaran menggunakan model pembelajaran POE dengan kelas yang mendapatkan pembelajaran konvensional. Dalam model pembelajaran POE langkah awal yang harus dilakukan adalah kemampuan memprediksi dikenal sebagai kemampuan untuk menyusun hipotesis (jawaban sementara). Setelah itu, guru menuliskan apa yang diprediksi siswa. Guru menanyakan kepada siswa, untuk menjawab pertanyaan-pertanyaan tersebut guru mengajak siswa melakukan kegiatan observasi, yaitu melakukan pengamatan melalui percobaan. Menurut Suparno ${ }^{[4]}$, pembelajaran dengan model Prediction, Observation and Explanation (POE) menggunakan tiga langkah utama yaitu: (a) Prediction, guru memberikan sebuah persoalan fisika kepada siswa, kemudian siswa merumuskan dugaan berdasarkan persoalan tersebut. Siswa diberi kebebasan seluas-luasnya dalam memberikan prediksi, (b) Observation, pada tahap ini siswa diajak melakukan percobaan, mengamati, atau melakukan pengukuran. Tujuan utama dilakukannya observasi adalah mencari tahu jawaban dari prediksi yang diberikan sisw, (c) Explaination, langkah terakhir membuat penjelasan, siswa diberi kesempatan untuk menjelaskan hasil observasi dan kesesuaiannya dengan prediksi awal. Dengan demikian siswa akan menemukan konsep sebenarnya dari persoalan fisika yang sedang dipelajari. 


\section{Metode Penelitian/Eksperimen}

Penelitian yang digunakan adalah penelitian komparatif dengan metode eksperimen. Menurut Sugiyono ${ }^{[5]}$, metode penelitian eksperimen dapat diartikan juga sebagai metode penelitian yang digunakan untuk mencari pengaruh perlakuan tertentu terhadap yang lain dalam kondisi yang terkendali. Berdasarkan tujuan yang ingin dicapai, maka dalam penelitian ini menggunakan rancangan penelitian berbentuk control pretest-posttest group design.

Tabel I. Desain Penelitian

\begin{tabular}{cccc}
\hline Group & Pre-test & Treatment & Post-test \\
\hline $\mathrm{E}_{1}$ & $\mathrm{O}_{\mathrm{I}}$ & $\mathrm{X}_{\mathrm{I}}$ & $\mathrm{O}_{2}$ \\
\hline $\mathrm{E}_{2}$ & $\mathrm{O}_{3}$ & $\mathrm{X}_{2}$ & $\mathrm{O}_{4}$ \\
\hline
\end{tabular}

EI merupakan kelompok eksperimen I, E2 adalah kelompok eksperimen II, OI adalah tes awal (pre-test) pada kelas eksperimen I, $\mathrm{O}_{2}$ adalah tes akhir (pos-ttest) pada kelas eksperimen $\mathrm{I}, \mathrm{O}_{3}$ adalah tes awal (pre-test) pada kelas eksperimen II, $\mathrm{O}_{4}$ adalah tes akhir (post-test) pada kelas eksperimen II.

Variabel bebas dalam penelitian ini adalah model pembelajaran Problem Based Learning (PBL) dan model pembelajaran Prediction, Observation and Explanation (POE), sedangkan variabel terikat dalam penelitian ini adalah hasil belajar fisika siswa kelas X di SMA Negeri 5 Lubuklinggau.

Teknik pengambilan sampel yang digunakan yaitu simple random sampling. Sampel yang di pakai saat penelitian yaitu kelas X.9 sebagai kelas eksperimen I dan X.5 sebagai kelas eksperimen II. Sebelum peneliti melakukan penelitian terhadap kelas eksperimen I dan kelas eksperimen II. Peneliti mengadakan uji coba instrumen soal. Uji coba instrumen soal ini dilaksanakan di kelas XI.IPA.I pada tanggal 3 Agustus 2015. Uji coba instrumen ini bertujuan untuk mengetahui validitas, reliabilitas, daya pembeda, dan tingkat kesukaran soal. Dengan di lakukannya uji instrumen peneliti dapat melihat kualitas soal yang digunakan sebagai alat pengumpul data untuk pre-test dan post-test. Teknik analisa data yang digunakan dalam penelitian ini meliputi rata-rata dan simpangan baku, simpangan baku, uji normalitas, uji homogenitas, dan uji hipotesis. Uji hipotesis yang digunakan dalam penelitian menggunakan uji-t. Menurut sudjana ${ }^{[6]}$, persamaan yang digunakan

$$
t=\frac{x_{1}-x_{2}}{s \sqrt{\frac{1}{n_{1}}+\frac{1}{n_{2}}}}
$$

dengan

$$
s=\sqrt{\frac{\left(n_{1}-1\right) s_{1}^{2}+\left(n_{2}-1\right) s_{2}^{2}}{n_{1}+n_{2}-2}}
$$

dengan $\overline{x_{1}}$ adalah nilai rata-rata kelompok eksperimen I, $\overline{x_{2}}$ adalah nilai rata-rata kelompok eksperimen II, $n_{1}$ adalah banyak sampel kelompok eksperimen I, $n_{2}$ adalah banyak sampel kelompok eksperimen II, $s$ adalah simpangan baku, $s_{1}{ }^{2}$ adalah varians kelompok eksperimen I, dan $s_{2}{ }^{2}$ adalah varians kelompok eksperimen II .

\section{Hasil Penelitian dan Pembahasan}

Berdasarkan analisa uji validitas butir soal untuk pretest dan posttest di peroleh 8 soal essay yang valid dari IO soal yang di ujikan. Sesudah uji intrumen langkah selanjutnya peneliti mengadakan pre-test di kelas eksperimen I dan eksperimen II. Berdasarkan analisis perhitungan data diketahui bahwa skor rata-rata kelas eksperimen I sebesar 56,8I dan skor rata-rata kelas eksperimen II sebesar 54,75. Dengan demikian dapat disimpulkan kemampuan awal siswa kelas eksperimen I dan kelas eksperimen II adalah sama. Sedangkan simpangan baku pre-test kelas eksperimen I adalah 5,7 dan simpangan baku pre-test kelas eksperimen II adalah 7,06.

Setelah pre-test peneliti pengadakan treatman, treatman Pada saat penerapan model pembelajaran problem based learning (PBL) dikelas eksperimen I dimulai, sama dengan pembelajaran di kelas eksperimen II yang menggunakan model pembelajaran prediction, observation and explanation (POE). Guru mengkomunikasikan tujuan pembelajaran secara jelas, menumbuhkan sikap-sikap yang positif terhadap pembelajaran, dan melaksanakan apa yang diharapkan untuk dilakukan oleh siswa. Guru menjelaskan bahwa pada model pembelajaran problem based learning (PBL) dan model pembelajaran prediction, observation and explanation (POE) di masing-masing kelas eksperimen tujuan utamanya adalah meningkatkan kemampuan siswa dalam aspek pemecahan masalah untuk menyelesaikan soal yang berbentuk pemecahan masalah.

Pertemuan di kelas eksperimen I dilaksanakan sebanyak 2 kali pertemuan, sedangkan untuk kelas eksperimen II juga dilaksanakan sebanyak 2 kali pertemuan. Selama proses pembelajaran berlangsung, di kelas eksperimen I siswa di dorong untuk mengajukan pertanyaan, mencari informasi dan mengungkapkan pendapatnya. Dalam hal ini guru bertindak sebagai pembimbing yang menyediakan bantuan, namun siswa berusaha untuk bekerja secara kelompok dalam menyelesaikan suatu permasalahan. Selanjutnya di akhir pelajaran, siswa di dorong untuk menyatakan ide-idenya secara terbuka dan bebas refleksi dari proses pembelajaran yang tadi dilakukan. Pada pertemuan pertama siswa masih belum mengikuti langkah-langkah model pembelajaran problem based 
learning (PBL), sehingga siswa merasa bingung dan hasil belajar siswa masih belum maksimal.

Pada kelas exsperimen I, siswa lebih dibimbing dalam mengenal model pembelajaran Problem Based Learning (PBL). Pada pertemuan kedua ini dari 35 siswa yang ada, hampir I8 siswa lebih santai dan menikmati pelajaran yang mengakibatkan mereka aktif dalam belajar. Siswa yang lain masih membutuhkan bimbingan guru dalam menerapkan konstektual. Untuk itulah peneliti mengadakan refleksi untuk melihat kelemahan mengajar. Pada pertemuan terakhir siswa lebih terlihat aktif. Hal ini dikarenakan model pembelajaran Problem Based Learning (PBL) merupakan suatu konsepsi yang membantu guru mengaitkan konten mata pelajaran dengan situasi dunia nyata dan motivasi siswa membuat.

Pada kelas eksperimen II dengan penerapan model pembelajaran prediction, observation and explanation (POE) disiswa di minta membuat prediksi dari LKS yang diberikan oleh guru. Setelah membuat prediksi, siswa melakukan observasi dan terakhir evaluasi. Pada kelas eksperimen II banyak siswa mengalami kesulitan. Hal ini dikarenakan mereka belum mengenal materi yang akan di ajarkan.sehingga mereka kesulitan untuk membuat prediksi. Model pembelajaran prediction, observation and explanation (POE) banyak memiliki kekurangan yaitu I) memerlukan persiapan yang lebih matang, terutama berkaitan penyajian persoalan kimia dan kegiatan eksperimen yang akan dilakukan untuk membuktikan prediksi yang diajukan peserta didik. 2) untuk melakukan pengamatan langsung memerlukan bahan-bahan, peralatan dan tempat yang memadai dan 3) untuk kegiatan eksperimen memerlukan kemampuan dan keterampilan yang khusus, sehingga guru dituntut untuk bekerja lebih professional

Pertemuan pertama untuk kelas eksperimen II dari 35 siswa hanya 2 siswa yang mampu menjawab pertanyaan dengan benar. Sisanya terlihat kurang aktif, hal ini mungkin disebabkan belum mampunya siswa mengikuti penerapan model pembelajaran Prediction, Observation and Explanation (POE) dimana disiswa di minta membuat prediksi. Sedangkan mereka saja belum mengenal materi yang akan di ajarkan. Pada kelas eksperimen II kendala yang ada timbul dari siswa yang masih terlihat kurang aktif dalam mengikuti KBM. Siswa tidak bersemangat dan tidak berminat dalam pembelajaran sehingga siswa menjadi pasif (tidak aktif), siswa mengikuti pembelajaran tidak ada niat, tidak ada gairah dan keseriusan. Jika guru mengajukan pertanyaanpertanyaan, siswa hanya diam, tidak ada yang menjawab atau merespon guru. Salah satu solusi untuk mengatasi ini adalah guru memberikan penerapan model pembelajaran yang berorientasi pada keaktifan siswa,

Dari hasil penelitian terbukti bahwa penggunaan model pembelajaran Problem Based Learning mampu meningkatkan hasil belajar fisika pada materi pengukuran.
Hal ini diperkuat berdasarkan hasil analisis data post-test Berdasarkan hasil analisis data post-test terdapat perbedaan hasil belajar antara kelas eksperimen I dengan kelas eksperimen II. Perbedaan hasil belajar yang disebabkan dari perlakuan yang diberikan pada kelas eksperimen I yang diajarkan dengan menggunkanan model pembelajaran problem based learning diperoleh nilai rata-rata berdasarkan uji-t pada taraf $\alpha=0,05$, diperoleh thitung $>$ tabel $(2,17>2,00)$ yang berarti ho ditolak dan ha diterima. Rata-rata akhir hasil belajar fisika kelas eksperimen I sebesar 73,4 sedangkan pada kelas kelas eksperimen II sebesar 69,I4.

Menurut Triyanto ${ }^{[7]}$, Dengan model pembelajaran problem based learning (PBL) mengajarkan siswa akan keterampilan-keterampilan kognitif penting dengan menciptakan pengalaman belajar, melalui permodelan perilaku tertentu dan kemudian membantu siswa mengembangkan keterampilan tersebut atas usaha mereka sendiri dengan pemberian semangat, dukungan dan suatu sistem scaffolding Selain itu, melalui pengajaran terbalik siswa diajarkan empat strategi pemahaman pengaturan diri spesifik yaitu perangkuman, pengajuan pertanyaan, pengklarifikasian dan prediksi sehingga siswa dituntut aktif selama proses kegiatan belajar mengajar berlangsung.

\section{Kesimpulan}

Berdasarlkan hasil penelitian dan pembahasan, dapat diperoleh kesimpulan bahwa hasila belajar fisika kelas eksperimen I lebih baik dari padda hasil belajar fisika kelas eksperimen II. Diperoleh thitung $>t_{\text {tabel }}(2,17>2,00)$ yang berarti ho ditolak dan $h_{a}$ diterima yang berarti ho ditolak dan ha diterima.

\section{Kepustakaan}

[I] Tampubolon, Togi dan Hambali, Taufi, Pengaruh Model Pembelajaran Problem Based Learning Terhadap Hasil Belajar Siswa Pada Materi Pokok Listrik Dinamis Kelas X MAS 'Ibadurrahman Stabat, vol.2, no.3, 20I4, I90-I98.

[2] Putra, Rizema, Desain Belajar Mengajar Kreatif Berbasis SAINS. Jogjakarta: DIVA Press, 2012

[3] Zulaeha., Darmadi, I Wayan., dan Werdhiana, Komang, Pengaruh Model Pembelajaran Predict, Observe, And Explain Terhadap Keterampilan Proses Sains Siswa Kelas X SMA Negeri I., vol.2, no.2, 20I4, I-8

[4] Suparno, Paul, Metodologi Pembelajaran Fisika. Yogyakarta: Universitas Sanata Dharma, 2007

[5] Sugiyono, Metode Penelitian Pendidikan Penelitian Kuantitatif, Kualitatif, dan R\&D. Bandung: Alfabeta, $201 \mathrm{I}$

[6] Sudjana, Metode Statistika, Bandung: Tarsito, 2005

[7] Trianto, Model-Model Pembelajaran Inofatif Berorientasi Kontruktivistik. Jakarta: Prestasi Pustaka Publisher, 2007 